Res Publica. Revista de Historia de las Ideas Políticas ISSN: $1576-4184$

\title{
Para una filosofía anti-meteorológica
}

\author{
A propósito de Ignacio Castro Rey, Ética del Desorden. Pánico y sentido \\ en el curso del siglo, Valencia, Pre-textos, 2017, 459 pp.
}

Rodrigo Castro Orellana*

Para escribir este libro se necesitaron 1000 días de soledad en la montaña y ni siquiera eso fue suficiente. Fue preciso que transcurrieran muchos años desde la salvaje introspección de Roxe de Sebes ${ }^{1}$ para que el trabajo de la cabaña adquiriese la forma de esta Ética del Desorden. El lenguaje tuvo que ser lentamente afilado para que alcanzara la dureza de un acero que nos clava. Porque esto es lo primero que ha hecho Ignacio Castro en este libro: crear palabras que son como cebos que pescan la presencia espectral de las cosas (360). Unas palabras que conducen al lector que las acompaña a caminar y atravesar lugares, a demorar la mirada en el entorno (261). Hay un cierto ejercicio fenomenológico en esta Ética del Desorden que, si bien evidencia su ascendiente filosófico, no se instala en el espacio de las polémicas teóricas para defender una idea frente a otra. El libro se abre a una exterioridad pre-conceptual en que las infinitas discrepancias convergen en un "sentido común" que nada tiene que ver con eso que muchas veces se llama "sentido común". Ética del Desorden no es un artefacto de guerra, sino más bien una violenta invitación al cese de las hostilidades para precisamente subvertir todo pragmatismo del "sentido común" y activar los verdaderos "sentidos comunes".

Si tuviese que decir algo a lo que se opone este libro lo denominaría "racionalidad meteorológica". Esa programación intensiva de cada una de las facetas de nuestra existencia que interrumpe una y otra vez nuestra relación con la vida desnuda. $\mathrm{La}$ permanente espectacularización de todo lo que sucede para no librar ningún resquicio a una ausencia de producción. Es aquello que Ignacio ilustra con la imagen del informe meteorológico que cada mañana nos dice qué sentir antes de asomarnos a la ventana (138). Contra esta represión de un vínculo sensorial con el mundo, contra esta represión que funciona por desvío, por incremento de minutos publicitarios, contra ella se pronuncia esta Ética del Desorden.

Tengo la impresión de que el libro puede ser muchas cosas. Una de ellas, aunque pueda parecer menor, consiste en la intrincada red que este libro teje con otras obras. Un libro sobre libros que puede ser usado como una guía para una lectura de nove-

\footnotetext{
Universidad Complutense de Madrid rodrigocastro@filos.ucm.es

1 Entendemos que, de alguna manera, Ética del Desorden constituye el libro que se anuncia una y otra vez en la crónica de la cabaña de Roxe de Sebes. Cf. I. Castro Rey, Roxe de Sebes. Mil días en la montaña, Madrid, Los libros de Frontera d, 2016.
} 
las, poemas y ensayos filosóficos. Alguien podría decirlo: un libro multiplicador que invita a leer muchos otros libros que se enlazan con aquello que Ignacio Castro busca en su escritura. Una escritura que recoge las huellas y los rastros de otras tantas escrituras para regresar al principio de la palabra donde resulta "necesario escuchar el silencio de las situaciones y la ambigüedad espectral de cualquier estancia" (437).

Para mí, Ética del Desorden pretende regresar al primer acto del drama filosófico, a un cara a cara originario entre ese desgarro que somos y la exterioridad silenciosa que nos envuelve. En dicha tesitura, este manifiesto anti-meteorológico despliega su reflexión mediante cinco episodios: percepción, intuición, espacio/tiempo, muerte y lenguaje. Me referiré a cada uno de ellos.

El primer tratado nos interpela con la pregunta: “¿Qué has visto hoy que no haya visto nadie?" porque en realidad estamos situados en un plano que ignora una vivencia elemental de la percepción. Hay una enorme dificultad para ver y quien no ve, no siente ni piensa. Nos falta una exterioridad que nos ubique frente a una comprensión anterior a todo concepto y que consiste en la pura simpleza del ver, el oír y el tocar. En este sentido, la percepción no es algo dado de antemano sino la primera gran lucha del ser humano (65). Una batalla que no persigue ninguna conquista desde una perspectiva objetiva. La percepción resulta exasperantemente heterogénea, ajena a cualquier normalización de las interpretaciones.

Si se lucha por algo es por una cercanía con las cosas. La poesía enseña este pensamiento elemental, este arte de la proximidad que subvierte el enclaustramiento solipsista de nuestra época. La sensibilidad parece convertirse en un acontecimiento excepcional cuando la cultura se despliega como una gigantesca "burocracia sensitiva" (70) que controla el menú de los sentidos programando minuciosamente el consumo del ojo. No sólo se nos dice a cada instante qué mirar o qué percibir, sino que además se nos indica el cómo y la intensidad que deben albergar nuestras percepciones.

Por esta razón, Ignacio Castro describe en su Ética del Desorden una huída de este mundo de la percepción asistida, abandonar el espacio protésico de una seguridad reglada, desconectarnos "de ese cuerpo global que nos protege de la percepción" (75) de un eterno aquí y ahora. Se trataría de poner en práctica quizás la única verdadera revolución, aquella que comienza en el individuo y que carcome la programación absoluta de nuestras existencias para introducir la brecha salvaje de un tiempo muerto en que se percibe el silencio de lo que no se quiere ver.

Dicha relación con una potencia ausente está también en el corazón de otra experiencia que trastoca las hegemonías de nuestro presente. A ella está dedicado el segundo tratado que conforma la Ética del Desorden. Me refiero a la intuición, esa "universalidad sin concepto" de la que hablaba Kant en su Crítica del Juicio². Ignacio la describe en su libro como algo que no es sentimiento ni presentimiento sino el "umbral de un concepto" (131), una frontera carente de método que simplemente emerge como un "accidente intelectual, inesperado y contingente" (172). Un acontecimiento que nace con la observación meticulosa, que se desliza sorpresivo en el hombre para conseguir "perforar la costra de las apariencias" (135) y situarnos ante una comprensión más cabal de las cosas.

Esto, sin lugar a dudas exige una necesaria interrupción, un violento desarraigo, un "golpe mental" (134) que nos coloca por fuera de todo el conocimiento acre-

Cf. I. Kant, Crítica del Juicio, Madrid, Tecnos, 2011, pp. 129-133. 
ditado que odia nuestro sexto sentido. Desde este punto de vista, la intuición, así como la percepción, también es un adversario de lo actual. Esto significa que va a contracorriente de la obturación colectiva que nos abotaga con mensajes espectaculares, novedades repetitivas, ideas que deben ser consumidas. Ética del Desorden nos muestra la época de aturdimiento en que habitamos donde el "camuflaje de la sombra de lo singular" (177) suprime la agudeza desenmascaradora de la intuición.

Pero percibir o intuir la exterioridad no pueden ser posibles sin una capacidad que permita vivir el presente en que se decide la vida (188). Hay que asumir la tarea épica de pensar el instante y de sostenerse en su eternidad. Sí, porque como nos enseña este libro, la eternidad no es la ausencia del tiempo sino su acumulación en el aquí y en el ahora. La inmensa "llanura impalpable del tiempo -cito a Ignacio-se precipita siempre de modo espacial; toma cuerpo en los sitios, en sus cosas, en los pequeños sucesos (...)" (193-194).

Una experiencia espacio-temporal completamente secuestrada por la cronología social que asigna a cada momento una función, una ocupación, un mensaje, una imagen o un anuncio (195). Este es el mayor pánico en el curso de nuestro siglo: el terror de enfrentar el vacío de un tiempo y un espacio sin coberturas, el silencio del desierto que crece, la incertidumbre de una experiencia sin definiciones impuestas. Pánico a una libertad inmediata (243), pánico "ante lo que sólo puede ocurrir en un instante de tiempo libre" (243). Vivimos una crisis de la presencia real (265), en la negación de lo eterno que es la continuidad de la finitud.

Por eso no existe nada que sea más destructivo para la producción capitalista que la muerte. Hay una exclusión de la posibilidad misma de un diálogo con los límites (285) porque el totalitarismo de la fluidez mercantil no acepta ser relativizado de ningún modo. Este horror al vacío se manifiesta, por ejemplo, en el silencio que invisibiliza la marea de suicidios, desapariciones y accidentes sin nombre que inunda la ciudad. Ética del Desorden nos sugiere mirar la arquitectura urbana como un complejo dispositivo que pretende "tapiar los huecos por los que se cuela la ley de gravedad en nuestras grandes capitales" (325). El urbanismo como una técnica de elaboración de muros para sujetos que desean arrojarse al abismo.

Por debajo o más allá de estas diversas modalidades de escapatoria subyace la seriedad de la muerte como ese absoluto que impone el deber de vivirlo todo en esta vida (276). Porque "cada minuto algo muere en nosotros" (278), la existencia que lo sabe ver asume que no es dueña de sí misma, que "está sostenida en un exterior inalcanzable" (350). Se trata de una tensión heroica (327) que nos desafía con su ejercicio y que rivaliza con los enormes prestigios sociales de la palabra "evasión".

Ansiamos el momento de la desconexión, esa experiencia que introduzca la novedad real que lo sacude y trastoca todo. Sin embargo, la continuidad sin alteraciones se prolonga envuelta en la "redundancia funcional de la comunicación y sus consignas" (374). Ignacio Castro ha escrito un libro que intenta dinamitar esta coacción de la expresión que no deja entrar el afuera. Su gesto involucra forzar la lengua para que se abra una brecha por la cual pueda filtrarse algún fragmento "del fondo negro del universo" (365)

En tal sentido, hay una experiencia que realizar en la lectura de Ética del Desorden, de la cual quizás se salga transformado. Un cara a cara con estas palabras cuidadosamente afiladas por su autor a lo largo del tiempo. En mi caso particular, no puedo dejar de deformar dichas palabras desde mis propias inquietudes personales y filosóficas. Al hacerlo no solamente identifico las virtudes de esta obra-que ya he 
mencionado- sino que también encuentro las zonas en las cuales corresponde establecer un debate con ella. Algo, por lo demás, que representa otra virtud: el mérito de un libro que nos hace pensar.

Para concluir, las apuntaré muy breve y esquemáticamente. No comparto el respeto que este libro tiene por Heidegger, con lo cual no quiero decir que este sea el autor más central dentro de la obra. Quizás lo sea Nietzsche, pero aquello que me distancia de Ética del Desorden sin lugar a dudas guarda relación con el filósofo de la Selva Negra.

No creo que haya existido un malentendido con la filosofía heideggeriana que nos bloquee (212) para captar el fondo espectral de dicho pensamiento. En mi opinión, el espectro heideggeriano no tiene nada que ver con el olvido de una naturaleza sigilosa que ama esconderse, asunto que le interesa a Ignacio. El espectro heideggeriano guarda relación más bien con el intento de ocultar la densidad histórica que determina mucho de lo que pensamos, decimos y hacemos. Solamente ese contexto permite advertir lo que subyace en la crítica heideggeriana de la modernidad, en su virulenta desconfianza respecto de la ciencia y la técnica o en sus acrobáticas genealogías de vocablos alemanes.

Un gesto intelectual que forma parte de la "revolución conservadora" de principios del siglo XX que sufrió la pérdida de la "totalidad orgánica" característica de la sociedad pre-moderna y que reaccionó a las imágenes sobre el porvenir que ofrecía el desarrollo del capitalismo y también la crítica marxista del mismo ${ }^{3}$. Por este motivo, en Heidegger emerge una especie de "populismo paradójico" que pretende reconciliar el culto al pueblo ("rural y provinciano") 4 con el odio aristocrático a una "Masa" uniforme en que se expresa la inautenticidad de "lo Uno"s.

Me parece que el magisterio de Heidegger ha producido una negativa degradación del ejercicio de la filosofía como ciencia y su confrontación con el arte como vía para llegar a la verdad (51). Todo esto dentro de una descomposición superficial de la Ilustración en partículas de dominación y pensamiento cuantitativo, que excluyen todo el proyecto crítico y emancipador que está contenido en la modernidad. Mi discusión con Etica del Desorden se inscribe dentro de este problema.

Me inquieta la radicalización del rechazo de la técnica y la ciencia como espacios de reflexividad para el ser humano. El cuestionamiento del concepto ilustrado de la historia que puede arrastrarnos a un actualismo ciego ante el valor del archivo (257). La denuncia sin paliativos de nuestro "desarraigo terrenal" (216) como si la naturaleza no tuviese también una violencia que sin duda agradecemos haber podido compensar. La confianza en una secreta verdad de las palabras que nos dirigiría a "las cosas en estado crudo" (361) cuando tal vez haya que permanecer en la superficie de las palabras y comprenderlas como una praxis. La reivindicación de un núcleo carnal

Para un desarrollo del concepto de "revolución conservadora" y del modo en que Heidegger se inscribe en dicho marco, cf. P. Bourdieu, La ontología política de Martin Heidegger, Barcelona, Paidós, 1988.

$4 \quad$ El máximo ejemplo de esta primera perspectiva se encuentra en el texto: Warum bleiben wir in der Provinz? (¿Por qué permanecemos en la provincia?).

5 Según Bourdieu, "la oposición entre el Eigentlichkeit, la «autenticidad», y la Uneigentlichkeit, la «inautenticidad», «modos cardinales del ser-ahí», como dice Heidegger, en torno de los cuales, desde el mismo punto de vista de las lecturas tan estrictamente internas, se organiza toda la obra, es una retraducción particular y particularmente sutil de la oposición común entre la «élite» y las «masas»”. Cf. P. Bourdieu, La ontología política de Martin Heidegger, op. cit., p. 81. 
del cristianismo (165) en el cual Dionisio ya no sería un antagonista de Cristo (248), cuando quizás Nietzsche tenga razón en su empeño por pensar la falta constitutiva del sujeto en un sentido laico.

En fin, son muchas las preguntas y cuestiones que podrían mencionarse, porque solo una obra filosófica honesta y que corre riesgos con la verdad puede darnos un estímulo para la discusión y el debate intelectual en una época excesivamente silenciosa como la nuestra. Este es el regalo que nos ha hecho Ignacio Castro, situándonos frente al pánico y el sentido que recorre nuestro siglo. 